TAVEIRA, R.Z. et al. Avaliação do ponderal de novilhos Nelore de diferentes linhagens submetidos a dois tipos de dieta no período das águas. PUBVET, Londrina, V. 5, N. 29, Ed. 176, Art. 1190, 2011.

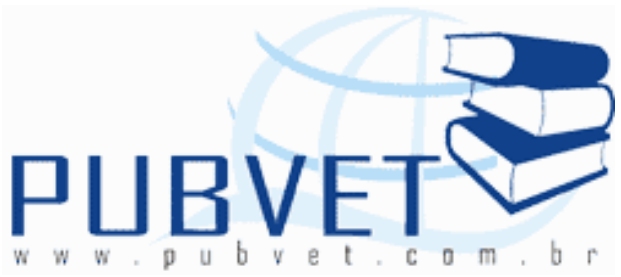

PUBVET, Publicações em Medicina Veterinária e Zootecnia.

\title{
Avaliação do ponderal de novilhos Nelore de diferentes linhagens submetidos a dois tipos de dieta no período das águas
}

Rodrigo Zaiden Taveira ${ }^{1}$, Evando Alves Filgueiras ${ }^{2}$, Rodrigo Medeiros da Silva ${ }^{3}$, Osvaldo José da Silveira Neto ${ }^{3}$, Ângelo Leonardo de Castro Basile ${ }^{3}$, Lindolfo Dorcino dos Santos Neto ${ }^{4}$, Jean Sardinha de Almeida ${ }^{4}$, Barbara Juliana Martins Lemos $^{5}$

${ }^{1}$ Professor Dr. do Curso de Zootecnia - UEG - São Luís de Montes Belos. Email: rodrigo.zaiden@ueg.br

${ }^{2}$ Bacharel em Zootecnia - UEG - São Luís de Montes Belos.

${ }^{3}$ Professor MSc. do Curso de Zootecnia da UEG - São Luís de Montes Belos-GO.

${ }^{4}$ Acadêmicos de Zootecnia - UEG - São Luís de Montes Belos.

${ }^{5}$ Mestranda em Ciência Animal - EVZ/UFG.

\section{Resumo}

Baixos níveis de ganho em peso durante a estação chuvosa impedem que a produção em pastagens tropicais seja capaz de atender aos mercados que exigem animais precoces e com bom desenvolvimento de carcaças. Foi realizado um experimento, no município de Nova Crixás, estado de Goiás, utilizando 60 novilhos da raça Nelore com idades entre 12 e 14 meses. Os animais foram escolhidos aleatoriamente, respeitando intervalo máximo de 3 meses de diferença na idade, tomando-se cuidado de dividir os filhos de um mesmo touro em ambos tratamentos, sendo: PSM: pastagem + sal mineral 
TAVEIRA, R.Z. et al. Avaliação do ponderal de novilhos Nelore de diferentes linhagens submetidos a dois tipos de dieta no período das águas. PUBVET, Londrina, V. 5, N. 29, Ed. 176, Art. 1190, 2011.

(tratamento controle); PSPE: pasto + suplemento protéico-energético. 0 suplemento foi fornecido ad libidum, com consumo médio estimado em torno de $0,1 \%$ do peso vivo cabeça/dia. Os animais permaneceram em pastagens de Brachiaria Brizantha cv. Marandu, durante 118 dias. As análises estatísticas foram realizadas por meio do programa estatístico SAS, e as médias das características comparadas pelo teste $t(p<0,05)$. Os animais que foram submetidos à suplementação protéico-energética mantiveram sempre os maiores pesos em relação ao lote controle, apresentando superioridade média de $32,9 \mathrm{~kg}$ na última pesagem. Houve inversão na classificação das linhagens avaliadas entre os tratamentos, demonstrando a existência de interação genótipo-ambiente no processo de produção. A suplementação protéicoenergética na época das águas proporcionou a produção de novilhos mais pesados, com média de $374,8 \mathrm{~kg}$, podendo ser utilizada na composição da dieta de novilhos ao sobreano criados em sistema de pastagens, objetivandose ganhos em pesos adicionais e a interação genótipo-ambiente deve ser considerada.

Palavras-chave: bovinos de corte; desempenho; suplementação.

\title{
Weight evaluation of Nellore yearlings from different lineage using two different types of diet in the water season
}

\begin{abstract}
Low levels in weight gain during the water season obstruct that the production in tropical pastures will be able to attentive the markets that demand precocity animals and with good carcass development.It was realized one experiment in the Nova Crixas city, Goias state, using 60 Nellore yearlings with ages ranging from 12 to 14 months. The animals were selected randomly, with maximum range of three months of age. The animals were divided in two treatments, being: PSM $=$ pasture + mineral supplementation (control treatment) and PSPE $=$ pasture + protein-energetic supplementation. The supplement was available ad libidum, with average intake estimated in $0.1 \%$ of the live weight
\end{abstract}


TAVEIRA, R.Z. et al. Avaliação do ponderal de novilhos Nelore de diferentes linhagens submetidos a dois tipos de dieta no período das águas. PUBVET, Londrina, V. 5, N. 29, Ed. 176, Art. 1190, 2011.

/head/day. The animals were kept in pasture of Brachiaria brizantha cv. Marandu during 118 days. The statically analysis were carried out by SAS program and the traits average compared by the $t$ test $(p<0.05)$. The animals that were submitted in protein-energetic supplementation maintained the highest weights considering the control treatment, showing average superiority of $32,9 \mathrm{~kg}$ in the last weighing. Could be observed that occur inversion in the ranking of lineage between the treatments, showing the genotypeenvironmental interaction in the process production. The proteinenergeticsupplementation in the water season, displayed heavier animals with average of $374.8 \mathrm{kgcan}$ be used in the alimentation of Nellore yearling kept in pasture, aiming extra weight gain, and the genotype-environmental interaction should be considered.

Keywords: beef cattle; performance, supplementation.

\section{Introdução}

Baixos níveis de ganho em peso durante a estação chuvosa têm como consequência mais importante, o fato de impossibilitar que os ganhos em peso anuais dos sistemas de produção baseados em pastagens tropicais sejam capazes de atender ao mercado moderno, o qual requer animais jovens e com carcaças pesadas. Nessas condições, o fator que limita o crescimento dos animais é a deficiência de proteína e energia nas dietas.

De modo geral, sistemas de produção baseados no uso exclusivo de pasto não utiliza todo o potencial genético do animal. Assim, para solucionar o impasse criado por essa dicotomia entre produção por animal e a produção por área, pode-se utilizar a suplementação alimentar durante o período das águas (Paulino et al., 2000).

A suplementação para bovinos em pastejo já vem sendo empregada quando a pastagem apresenta deficiências que impedem o animal de produzir ou se reproduzir de forma satisfatória. Ganhos em peso elevados dependem principalmente do suprimento adequado de aminoácidos e de energia aos 
TAVEIRA, R.Z. et al. Avaliação do ponderal de novilhos Nelore de diferentes linhagens submetidos a dois tipos de dieta no período das águas. PUBVET, Londrina, V. 5, N. 29, Ed. 176, Art. 1190, 2011.

tecidos dos bovinos, o que provavelmente não ocorre em pastejo exclusivo (Santos et al., 2008).

No período das águas, quando acontece a máxima produção das forrageiras associada a maior capacidade de suporte, os ganhos podem ser maximizados mediante o uso de suplementação protéico e energética. Entretanto, considerando-se a interação genótipo-ambiente, existe a necessidade de se buscar animais de melhor valor genético, os quais possas eficientemente responder à suplementação, adequando a melhor genética ao ambiente específico de produção.

Sendo assim, objetivou-se comparar o desenvolvimento de 60 novilhos da raça Nelore, de diferentes linhagens, ao sobreano, submetidos a dois distintos tratamentos, sendo, PSM: (pastagem de Brachiária Brizanthacv. Marandu + suplementação mineral); PSPE: (pastagem de Brachiária Brizantha cv. Marandu + suplementação protéico-energética), a fim de verificar se existem ganhos em peso adicionais mediante a suplementação no período das águas, bem como avaliar a influência da interação genótipo-ambiente nos diferentes tratamentos.

\section{Material e Métodos}

O experimento foi conduzido no município de Nova Crixás, estado de Goiás. Foram utilizados ao todo 60 novilhos da raça Nelore, divididos nas linhagens Karvadi, Nova Opção, Nacional e Taj Mahal, cada qual representada por 15 animais.

Os animais foram divididos em dois tratamentos, sendo: T1 - PSM (pastagem de Brachiária Brizantha cv. Marandu + suplementação mineral); T2 - PSPE (pastagem de Brachiária Brizantha cv. Marandu + suplementação protéico-energética), de modo que todas as linhagens estivessem presentes nos dois tratamentos. O suplemento foi fornecido ad libidum, com consumo médio estimado em torno de $0,1 \%$ do peso vivo cabeça/dia. O suplemento protéico-energético continha $45 \%$ de proteína bruta, $18 \%$ de fósforo, $4 \%$ de 
TAVEIRA, R.Z. et al. Avaliação do ponderal de novilhos Nelore de diferentes linhagens submetidos a dois tipos de dieta no período das águas. PUBVET, Londrina, V. 5, N. 29, Ed. 176, Art. 1190, 2011.

sal comum e $11 \%$ de uréia. 0 mesmo era composto por: Proteína bruta $=450$ $\mathrm{g}$; NDT=600 g; Cálcio $=25 \mathrm{~g}$; Cobalto $=03 \mathrm{mg}$; Cobre $=250 \mathrm{mg}$; Cromo $=$ $5,70 \mathrm{mg}$; Enxofre $=10 \mathrm{~g}$; Flúor $=160 \mathrm{mg} ;$ Fósforo $=16 \mathrm{~g}$; Iodo $=10 \mathrm{mg}$; Manganês $=400 \mathrm{mg}$; Selênio $=03 \mathrm{mg}$; Sódio $=15 \mathrm{~g}$ e Zinco $=700 \mathrm{mg}$.

Os animais permaneceram em pastagens de Brachiária Brizantha cv. Marandu durante 118 dias. As pesagens foram realizadas a cada 32 dias após jejum alimentar de 12 horas. O período de adaptação utilizado foi de 20 dias.

As variáveis avaliadas foram provenientes de quatro pesagens para cada tratamento avaliado, sendo: P1 (primeira pesagem após o período de adaptação); P2 (segunda pesagem); P3 (terceira pesagem); P4 (última pesagem); GP1 (ganho em peso entre P1 e P2); GP2 (ganho em peso entre P2 e P3); GP3 (ganho em peso entre P3 e P4) e GP4 (ganho em peso entre P1 e P4).

As informações de desempenho dos novilhos foram utilizadas para o ranqueamento das quatro linhagens paternas avaliadas em: elite, superior e regular, tendo como base a variação do desvio-padrão da média do ganho em peso final, em ambos os tratamentos.

As análises estatísticas foram realizadas por meio da utilização do programa estatístico SAS, e as médias das características comparadas pelo teste $t(p<0,05)$.

\section{Resultados e Discussão}

Pela avaliação dos dados contidos na Tabela 1, percebe-se que ambos os tratamentos apresentaram acréscimo nos valores médios de seus pesos, em torno de $17 \%$ e $22 \%$, para PSM e PSPE, respectivamente. 
TAVEIRA, R.Z. et al. Avaliação do ponderal de novilhos Nelore de diferentes linhagens submetidos a dois tipos de dieta no período das águas. PUBVET, Londrina, V. 5, N. 29, Ed. 176, Art. 1190, 2011.

Tabela 1. Médias, desvios-padrões (DP), valores máximo e mínimo dos animais pertencentes ao tratamento 1 e tratamento 2 , tendo em vista a primeira pesagem (P1), segunda pesagem (P2), terceira pesagem (P3) e quarta pesagem (P4).

\begin{tabular}{|c|c|c|c|c|c|c|c|c|}
\hline & \multicolumn{2}{|c|}{ P1 } & \multicolumn{2}{|c|}{ P2 } & \multicolumn{2}{|c|}{ P3 } & \multicolumn{2}{|c|}{ P4 } \\
\hline & $\begin{array}{l}\text { PSM } \\
\text { (T1) }\end{array}$ & $\begin{array}{c}\text { PSPE } \\
(\mathrm{T} 2)\end{array}$ & $\begin{array}{l}\text { PSM } \\
\text { (T1) }\end{array}$ & $\begin{array}{c}\text { PSPE } \\
(\mathrm{T} 2)\end{array}$ & $\begin{array}{l}\text { PSM } \\
(T 1)\end{array}$ & $\begin{array}{c}\text { PSPE } \\
\text { (T2) }\end{array}$ & $\begin{array}{l}\text { PSM } \\
(\mathrm{T} 1)\end{array}$ & $\begin{array}{c}\text { PSPE } \\
\text { (T2) }\end{array}$ \\
\hline $\begin{array}{l}\text { Média } \\
(\mathrm{Kg})\end{array}$ & $292,4^{\text {nss }}$ & $306^{\mathrm{ns}}$ & $305,80^{*}$ & $332,60^{*}$ & $327,55^{*}$ & $350,95^{*}$ & $341,90^{*}$ & $374,85^{*}$ \\
\hline $\begin{array}{l}\mathrm{DP} \\
(\mathrm{Kg})\end{array}$ & 31,12 & 24,12 & 29,80 & 25,85 & 28,44 & 27,10 & 28,16 & 29,40 \\
\hline $\begin{array}{l}\text { V.mín } \\
(\mathrm{Kg})\end{array}$ & 246 & 260 & 262 & 289 & 285 & 300 & 290 & 326 \\
\hline $\begin{array}{l}\text { V.máx } \\
(\mathrm{Kg})\end{array}$ & 339 & 341 & 347 & 378 & 375 & 401 & 380 & 430 \\
\hline
\end{tabular}

$\mathrm{ns}=$ não significativo pelo teste $\mathrm{t}(\mathrm{p}>0,05)$

$*=$ significativo pelo teste $t(p<0,05)$

Os animais que foram submetidos à suplementação protéico-energética mantiveram sempre os maiores pesos em relação ao lote controle, apresentando diferença final de $32,9 \mathrm{~kg}$ entre PSM e PSPE, na última pesagem. Este resultado se explica, em parte, conforme Santos et al., (2008), pelo aporte extra de nitrogênio e energia para a microbiota ruminal, provenientes da uréia, amido e proteína degradável no rúmen, contida no suplemento.

Através da Tabela 2, percebe-se que houve superioridade nos ganhos (GP1, GP3 e GP4) para os animais pertencentes ao PSPE (suplementação protéico-energética) em relação ao PSM (grupo controle), evidenciando o incremento de peso proporcionado pela suplementação. Entretanto, quando avaliado o GP2, percebe-se que não houve diferença estatística $(p>0,05)$ entre os tratamentos. Analisando apenas O GP4, observa-se que os animais pertencentes ao PSPE tiveram ganho diário, nesse período, superior em $190 \mathrm{~g}$ em relação aos pertencentes ao PSM. Esse ganho, ainda encontra-se inferior as $205 \mathrm{~g}$ de ganho diário registrados por Euclides et al., (2001), estudando 
TAVEIRA, R.Z. et al. Avaliação do ponderal de novilhos Nelore de diferentes linhagens submetidos a dois tipos de dieta no período das águas. PUBVET, Londrina, V. 5, N. 29, Ed. 176, Art. 1190, 2011.

ganhos diários em novilhos da raça Nelore com e sem suplementação protéicoenergética.

Tabela 2. Médias e desvios-padrões (DP) dos ganhos em pesos médios diários (GP1, GP2, GP3 e GP4), dos animais pertencentes ao tratamento 1 e tratamento 2 .

\begin{tabular}{lcccccccc}
\hline & \multicolumn{2}{c}{ GP1 } & \multicolumn{2}{c}{ GP2 } & \multicolumn{2}{c}{ GP3 } & \multicolumn{2}{c}{ GP4 } \\
\cline { 2 - 9 } & PSM & PSPE & PSM & PSPE & PSM & PSPE & PSM & PSPE \\
& $(\mathrm{T} 1)$ & $(\mathrm{T} 2)$ & $(\mathrm{T} 1)$ & $(\mathrm{T} 2)$ & $(\mathrm{T} 1)$ & $(\mathrm{T} 2)$ & $(\mathrm{T} 1)$ & $(\mathrm{T} 2)$ \\
\hline Média (g) & $390^{*}$ & $750^{*}$ & $770^{\text {ns }}$ & $650^{\text {ns }}$ & $390^{*}$ & $660^{*}$ & $505^{*}$ & $695^{*}$ \\
DP (g) & 0,04 & 0,06 & 0,06 & 0,06 & 0,04 & 0,05 & 0,02 & 0,02
\end{tabular}

$\mathrm{ns}=$ não significativo pelo teste $\mathrm{t}(\mathrm{p}>0,05)$

$*=$ significativo pelo teste $t(p<0,05)$

No desempenho das linhagens paternas avaliadas em relação ao ganho em peso médio de seus descendentes no grupo de animais submetidos à suplementação, destacaram-se as linhagens Taj Mahal e Nacional. Os animais pertencentes à primeira apresentaram maior ganho em peso médio diário (745 g) do que os pertencentes à segunda, porém esta, apresentou $50 \%$ de seus descendentes classificados entre elite e superior, tendo em vista a avaliação do ganho em peso médio diário. Este comportamento condiz com as observações realizadas por Oliveira et al., (2002), os quais evidenciaram superioridade na capacidade de ganho em peso de animais da linhagem Taj Mahal no período de pós-desmame. Os mesmos autores relatam ainda que os animais da linhagem Nacional tendem a apresentar musculatura bem desenvolvida e ótima diferença esperada na progênie (DEP) para ganho em peso ao sobreano.

Considerando o desempenho das linhagens paternas dos animais que integravam o grupo que não receberam suplementação protéico-energética, destacam-se as linhagens Nova Opção e Karvadi. A primeira apresentou o maior ganho em peso do grupo (561 g/dia), entretanto, a segunda linhagem apresentou $50 \%$ de seus descendentes classificados como elite e superior na avaliação do ganho em peso médio diário. O bom desempenho dessas linhagens pode ser explicado por Magnabosco et al., (1997), os quais relatam 
TAVEIRA, R.Z. et al. Avaliação do ponderal de novilhos Nelore de diferentes linhagens submetidos a dois tipos de dieta no período das águas. PUBVET, Londrina, V. 5, N. 29, Ed. 176, Art. 1190, 2011.

que animais da linhagem Karvadi possuem grande potencial de adaptação aos ambientes das pastagens brasileiras.

Pode ser observado que houve inversão na classificação das linhagens entre os tratamentos. Este comportamento demonstra a existência da interação genótipo-ambiente sobre a produção. Esta interação também foi constatada por Lopes et al., (2008), os quais constataram alterações na ordem de classificação de reprodutores da raça Nelore, mediante a avaliação de sua progênie.

Deve-se ressaltar que no presente estudo não foram avaliadas as linhagens maternas dos novilhos, além de outros fatores como a idade da vaca ao parto, ordem de parição e habilidade materna, os quais exercem influência sobre a expressão do máximo potencial de ganho em peso de um animal.

\section{Conclusões}

A suplementação protéico-energética na época das águas pode ser utilizada na composição da dieta de novilhos ao sobreano criados em pastagens, objetivando-se ganhos adicionais.

A escolha da linhagem paterna a ser utilizada encontra-se pautada na definição do tipo de sistema de criação que será utilizado, vez que a interação genótipo-ambiente exerce influência no desempenho dos animais.

\section{Referências Bibliográficas}

EUCLIDES, V.P.B. et al. Desempenho de novilhos F1 Angus-Nelore em pastagens de Brachiaria decumbens submetidos a diferentes regimes alimentares. Revista Brasileira de Zootecnia, v.30, n.2, p.451-458, 2001.

LOPES, J.S. et al. Efeito da interação genótipo-ambiente sobre o peso ao nascimento aos 205 e aos 550 dias de idade de bovinos da raça Nelore na Região Sul do Brasil. Revista Brasileira de Zootecnia., v.37, n.1, p.54-60, 2008.

MAGNABOSCO, C.U. et al. Catálogo de linhagens do germoplasma zebuíno. Brasília: Embrapa-Cenargem, 52 p. 1997. 
OLIVEIRA, J.H.F.; MAGNABOSCO, C.U.; BORGES, A.M.S. Nelore: Base genética e evolução seletiva no Brasil. Planaltina, DF: Embrapa Cerrados, Documento 49, 54 p. 2002.

PAULINO, M.F. et al. Suplementação de novilhos mestiços em pastagens de Brachiária decumbensdurante o período das águas. In: Reunião Anual da Sociedade Brasileira de Zootecnia, Viçosa 2000. Anais...Viçosa: SBZ. 2000.

SANTOS, F.A.P.; COSTA, D.C.F.; GOULART, R.C.D. Suplementação de bovinos de corte em pastagens: Conceitos atuais e aplicações. 2008. 